
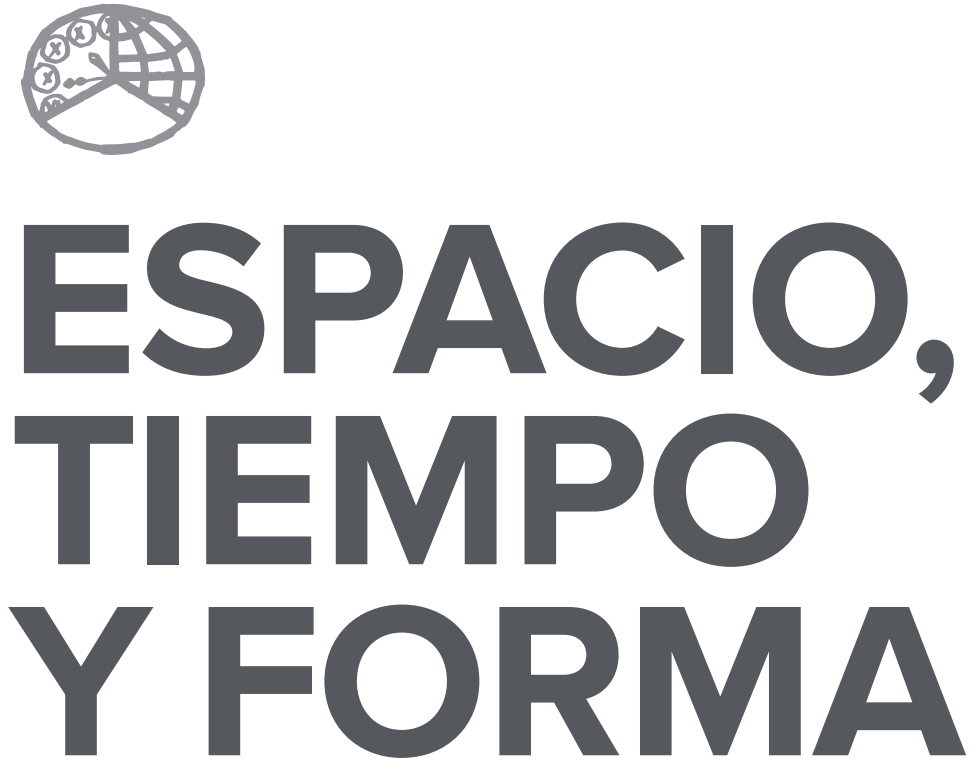

AÑO 2021

ISSN 0214-9745

E-ISSN 2340-1362

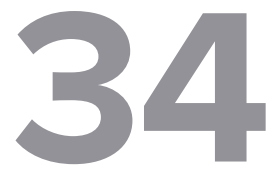

SERIE III HISTORIA MEDIEVAL

REVISTA DE LA FACULTAD DE GEOGRAFÍA E HISTORIA

VOLUMEN II 


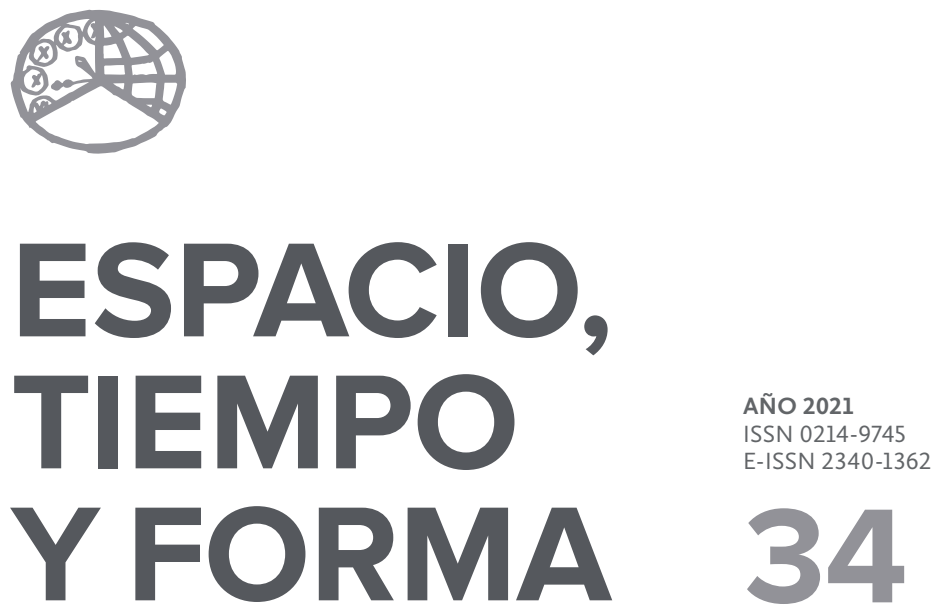

SERIE III HISTORIA MEDIEVAL

REVISTA DE LA FACULTAD DE GEOGRAFÍA E HISTORIA

VOLUMEN II

http://dx.doi.org/10.5944/etfiii.34.2021

\section{UกED}

UNIVERSIDAD NACIONAL DE EDUCACIÓN A DISTANCIA 
La revista Espacio, Tiempo y Forma (siglas recomendadas: ETF),

de la Facultad de Geografía e Historia de la UNED, que inició su publicación el año 1988, está organizada de la siguiente forma:

$$
\begin{aligned}
& \text { SERIE I - Prehistoria y Arqueología } \\
& \text { SERIE II - Historia Antigua } \\
& \text { SERIE III - Historia Medieval } \\
& \text { SERIE IV - Historia Moderna } \\
& \text { SERIE V - Historia Contemporánea } \\
& \text { SERIE VI - Geografía } \\
& \text { SERIE VII - Historia del Arte }
\end{aligned}
$$

Excepcionalmente, algunos volúmenes del año 1988 atienden a la siguiente numeración:
N. ${ }^{\circ} 1 \quad-$ Historia Contemporánea
N. ${ }^{\circ} 2-$ Historia del Arte
N. ${ }^{\circ} 3-$ Geografía
N. ${ }^{\circ} 4 \quad-$ Historia Moderna

ETF no se solidariza necesariamente con las opiniones expresadas por los autores.

UNIVERSIDAD NACIONAL DE EDUCACIÓN A DISTANCIA

Madrid, 2021

SERIE III - HISTORIA MEDIEVAL N. ${ }^{\circ} 34,2021$

ISSN 0214-9745 · E-ISSN 2340-1362

DEPÓSITO LEGAL M-21037-1988

URL: ETF III · HISTORIA MEDIEVAL · http://revistas.uned.es/index.php/ETFIII

DISEÑO Y COMPOSICIÓN

Carmen Chincoa Gallardo · http://www.laurisilva.net/cch

Impreso en España $\cdot$ Printed in Spain 
Espacio, Tiempo y Forma. Serie III. Historia Medieval es la revista científica fundada en I988 que publica el Departamento de Historia Medieval y Ciencias y Técnicas Historiográficas de la Facultad de Geografía e Historia de la UNED. Está dedicada al estudio de la Historia Medieval y acoge trabajos inéditos de investigación, en especial artículos que constituyan una aportación novedosa, que enriquezcan el campo de estudio que abordan y que ofrezcan una perspectiva de análisis crítico. Va dirigida preferentemente a la comunidad científica y universitaria, tanto nacional como internacional, así como a todos los profesionales de la Historia Medieval en general. Su periodicidad es anual y se somete al sistema de revisión por pares ciegos. La revista facilita el acceso sin restricciones a todo su contenido desde el momento de su publicación en edición electrónica. Espacio, Tiempo y Forma. Serie III. Historia Medieval se publica en formato electrónico y en papel.
Espacio, Tiempo y Forma. Serie III. Historia Medieval (Space, Time and Form. Series III. Medieval History) is a peerreviewed academic journal founded in I988 and published by the Department of Medieval History and Historiographical Sciences and Techniques at the Faculty of Geography and History, UNED. It is devoted to the study of Medieval History and is addressed to the Spanish and international scholarly community, as well as to professionals in the field of Medieval History. The journal welcomes previously unpublished articles, particularly works that provide an innovative approach, contribute to its field of research and offer a critical analysis. It is published annually. The journal provides complete open access to its content available online upon publication. Espacio, Tiempo y Forma. Serie III. Historia Medieval is published online and in print and is indexed in the databases and directories enumerated below.

Espacio, Tiempo y Forma. Serie III. Historia Medieval está registrada e indexada en Repertorios Bibliográficos y Bases de Datos nacionales e internacionales, como recomiendan los criterios de la Comisión Nacional Evaluadora de la Actividad Investigadora: LATINDEX, DICE, ISOC (CINDOC), RESH, INRECH, Dialnet, e-spacio UNED, CIRC 2.o (20I6), MIAR, FRANCIS, PIO, Ulrich's, SUDOC, ZDB, ERIH (ESF), REDIB, Repertorio de Medievalismo Hispánico, Directory of Open Access Journals (DOAJ), Emerging Sources Citation Index (ESCI), SCOPUS. La revista ha obtenido el Sello de Calidad de la FECYT (20I8).

\section{EQUIPO EDITORIAL}

Edita: Departamento de Historia Medieval y Ciencias y Técnicas Historiográficas, Universidad Nacional de Educación a Distancia

Director del Consejo de Redacción: Enrique Cantera Montenegro (UNED)

Editores: Enrique Cantera Montenegro (UNED), Carlos Barquero Goñi (UNED) 
CONSEJO DE REDACCIÓN

Cristina Álvarez Millán

Departamento de Historia Medieval y Ciencias y Técnicas Historiográficas, UNED

Ana Arranz Guzmán

Universidad Complutense de Madrid

Carlos de Ayala Martínez

Universidad Autónoma de Madrid

Carlos Barquero Goñi

Departamento de Historia Medieval y Ciencias y Técnicas Historiográficas, UNED

Enrique Cantera Montenegro

Departamento de Historia Medieval y Ciencias y Técnicas Historiográficas, UNED

Ana Echevarría Arsuaga

Departamento de Historia Medieval y Ciencias y Técnicas Historiográficas, UNED

José María de Francisco Olmos

Universidad Complutense de Madrid

María Jesús Fuente Pérez

Universidad Carlos III de Madrid

Manuel Fernando Ladero Quesada

Departamento de Historia Medieval y Ciencias y Técnicas Historiográficas, UNED

Paulina López Pita

Departamento de Historia Medieval y Ciencias y Técnicas Historiográficas, UNED

José Miguel López Villalba

Departamento de Historia Medieval y Ciencias y Técnicas Historiográficas, UNED

José María Monsalvo Antón

Universidad de Salamanca

Isabel Montes Romero-Camacho

Universidad de Sevilla

Gonzalo Viñuales Ferreiro

Universidad Rey Juan Carlos

COMITÉ CIENTÍFICO

Vicente Ángel Álvarez Palenzuela

Universidad Autónoma de Madrid

Daniel Baloup

Université de Toulouse-Le Mirail

Vicente García Lobo

Universidad de León

María Estela González de Fauve

Universidad de Buenos Aires · Fundación para la Historia de España

César González Mínguez

Universidad del País Vasco 
Nikolas Jaspert

Ruhr-Universität Bochum, Alemania

DIRECTORA DE ETF SERIES I-VII

Yayo Aznar Almazán

Decana Facultad de Geografía e Historia, UNED

SECRETARIO DE ETF SERIES I-VII

Julio Fernández Portela

Departamento de Geografía, UNED

GESTORA PLATAFORMA OJS

Carmen Chincoa Gallardo

COMITÉ EDITORIAL DE ETF SERIES I-VII

Carlos Barquero Goñi, Departamento de Historia Medieval y Ciencias y Técnicas Historiográficas, UNED; Enrique Cantera Montenegro, Departamento de Historia Medieval y Ciencias y Técnicas Historiográficas, Uned; Pilar Díez del Corral Corredoira, Departamento de Historia del Arte, UneD; Carmen Guiral Pelegrín, Departamento de Prehistoria y Arqueología (Arqueología), Uned; Patricia Hevia Gómez, Departamento de Prehistoria y Arqueología (Arqueología), unED; Luiza lordache Cârstea, Departamento de Historia Contemporánea, UNED; M. ${ }^{a}$ Luisa de Lázaro Torres, Departamento de Geografía, Uned; David Martín Marcos, Departamento de Historia Moderna, Uned; José Antonio Martínez Torres, Departamento de Historia Moderna, Uned; Íñigo García Martínez de Lagrán, Departamento de Prehistoria y Arqueología (Prehistoria), UnED; Álvaro Molina Martín, Departamento de Historia del Arte, unED; Francisco Javier Muñoz Ibáñez, Departamento de Prehistoria y Arqueología (Prehistoria), UNED; Rocío Negrete Peña, Departamento de Historia Contemporánea, UNED; Miguel Ángel Novillo López, Departamento de Historia Antigua, UnED.

CORRESPONDENCIA

Revista Espacio, Tiempo y Forma

Facultad de Geografía e Historia, UNED

c/ Senda del Rey, 7

28040 Madrid

e-mail: revista-etf@geo.uned.es 



\section{SUMARIO · SUMMARY}

\section{VOLUMEN I}

13 Artículos $\cdot$ Articles

15 Patricia A. Argüelles Álvarez

Peligros, inseguridades y problemas del viajero visigodo

Danger, Lack of Safety and Problems for the Visigothic Traveller

37 Carmen Barceló, Ana labarta, Josep Benedito \& José M. Melchor Cuatro cerámicas con epigrafía árabe del Museu de Borriana

Four Ceramic Pieces with Arabic Inscriptions in the Archeological Museum of Borriana

65 Carlos Barquero Goñ

Organización de la Orden de San Juan en Castilla durante los siglos XII y XIII The Organization of the Order of Saint John in Castile during the Twelfth and Thirteenth Centuries

113 Francisco de Paula Cañas Gálvez

Una infanta de Navarra en la corte de Castilla: escenarios políticos en torno a la configuración y evolución del Hostal y la casa de Blanca de Trastámara, Princesa de Asturias (I424-†I464)

A Princess of Navarre in the Court of Castile: Political Scenarios in the Configuration and Evolution of the Hostal and Royal Household of Blanca of Trastámara, Princess of Asturias (I424-†I464)

165 David Caramazana Malia

Las promociones artísticas de Alonso de Ejea, arzobispo y administrador perpetuo de la Archidiócesis de Sevilla y patriarca de Constantinopla (I403-I4I7)

The Artistic Patronage of Alonso de Ejea, Archbishop and Perpetual Administrator of the Archdiocese of Seville and Patriarch of Constantinople (I403-I4I7) 
203 Pedro Castillo Maldonado

Privilegios episcopales: la inviolabilidad de los obispos visigóticos y el delito de lesa majestad

Episcopal Privileges: The Inviolability of Visigothic Bishops and the Crime of Lèse-Majesté

227 Máximo Diago HERnANDO

Alonso de Fonseca, Obispo de Ávila, Cuenca y Osma, y el ascenso de un linaje de exiliados portugueses en la Castilla de los siglos XV y XVI Alonso de Fonseca, Bishop of Ávila, Cuenca and Osma, and the Promotion in Castile of an Exiled Noble Family from Portugal during the Fifteenth and Sixteenth Centuries

263 Antonio PIO DI Cosmo

Santa Brigida ed il Monte Gargano: un paesaggio dell'anima. La descrizione dell'ambiente come stratagemma d'ammaestramento morale Saint Brigid and Mount Gargano: A Landscape of the Soul. The Description of the Environment as a Device for Moral Instruction

Santa Brígida y el Monte Gargano: un paisaje del alma. La descripción del medio ambiente como estrategia de entrenamiento moral

293 FERRAN ESQUiLACHE

La 'fila' de agua valenciana y otras medidas de aforo. La verdadera naturaleza de un sistema de medición de caudales de origen andalusí

The Valencian Water 'Fila' and other Systems of Gauging Liquid Capacity. The Actual Nature of a Measurement System of Water Flow of Andalusí Origin

323 Alejandro Esteban Álvarez

Habices del Reino de Granada averiguados en I528 y I53I: la țā‘a nazarí de Órgiva (Alpujarra)

Habices of the Kingdom of Granada Ascertained in 1528 and I53I: The Nasrid tạa'a of Órgiva (Alpujarra)

359 Javier Gómez Gómez e Iñakı Martín Viso

Rationes y decimas: evidencias sobre la gestión de las sernas en el siglo Xl en el noroeste de la Península Ibérica

Rationes and Decimas: Some Evidences on the Management of Eleventh Century Sernas in Northwestern Iberia 
383 Santiago González Sánchez

Aportaciones de Paredes de Nava a las campañas militares del Infante Don Fernando, señor de la villa y regente de Castilla, contra el Reino Nazarí de Granada en I407 y en I4IO

The Contribution of Paredes de Nava to the Military Campaigns of the Infante Fernando, Lord of the Town and Regent of Castile, against the Nasrid Kingdom of Granada in 1407 and I4IO

429 ANTONI LLIBRER ESCRIG

Una máquina para la industria medieval. Los batanes del sur valenciano: integración y negocio. Nuevas aportaciones (I49O-I502)

A Machine for Medieval Industry. The Fulling Mills of the Valencian South: Integration and Business. New contributions (I49O-I502)

455 José Miguel López Villalba

Comunicación escrita y oral de la ordenanza municipal (siglos XV-XVI) Written and Oral Communication of Municipal Regulations (FifteenthSixteenth Centuries)

501 Emilio Martín Gutiérrez

El aprovechamiento de los recursos naturales: la grana en Andalucía occidental durante el siglo XV

The Use of Natural Resources: Grana Pigmentin Western Andalusia during the Fifteenth Century

\section{VOLUMEN II}

537 Vera-Cruz Miranda Menacho

Las finanzas de un heredero: Carlos de Aragón y Navarra (I42I-I46I)

A Crown Prince's Finances: Charles of Aragon and Navarre (I42I-I46I)

569 Raúl Morales Muñoz

Hacia una revalorización del conciliarismo hispano bajomedieval: el Defensorium Trium Conclusionum de Alfonso de Madrigal

Towards a Reappraisal of Late-Medieval Hispanic Conciliarism: Alfonso de Madrigal's Defensorium Trium Conclusionum 
605 David Nogales Rincón

Enrique III de Castilla (I390-I406) y la indagación de rentas: un proyecto regio para la búsqueda de mineros y tesoros a inicios del cuatrocientos Enrique III of Castile (I390-I406) and the Inquiry into Sources of Revenue: A Royal Project for the Quest of Mines And Treasures at the Turn of the Fifteenth Century

647 Gonzalo Oliva Manso

Seisenes y novenes. Tiempos de calma para la moneda castellano-leonesa (I282-I3I2)

The Seisén and the Novén. Times of Stability for the Castile-Leonese Currency (I282-I3I2)

685 Alberto Peña Fernández y Manuel García Alonso Una inscripción medieval inédita en la iglesia de San Miguel de Aguayo (Cantabria)

A Newly Found Medieval Inscription in the Church of San Miguel de Aguayo (Cantabria)

713 Rodrigo Pousa Diéguez

Configuración institucional de una villa costera: Muros en el tránsito de la Edad Media a la Edad Moderna

The Institutional Development of a Coastal Village: Muros between the Middle Ages and the Early Modern Times

745 Juan A. Prieto Sayagués

Las profesiones femeninas de la nobleza y de las oligarquías urbanas en la Castilla bajomedieval. Causas, dinámicas, privilegios y donaciones

Female Professions among the Nobility and the Urban Oligarchy in Late Medieval Castile. Causes, Dynamics, Privileges and Donations

815 María del Pilar Rábade Obradó

El miedo a la Inquisición en la Castilla de los Reyes Católicos

Fear of the Inquisition in Castile under the Catholic Monarchs

845 Carlos Manuel Reglero de la Fuente

EL abad contra el rey (y los regidores): conflicto de jurisdicciones y ejercicio del poder en Sahagún (I398-I4I7)

The Abbot versus The King (and the Town Councillors): Conflict between Jurisdictions and the Use of Power in Sahagún (I398-I4I7) 
881 Manuel Alejandro Rodríguez de la Peña

Eusebius and Alcuin on Constantine and Charlemagne as Wise Rulers:

Sapiential Rulership in Late Antiquity and the Early Middle Ages

Constantino y Carlomagno como gobernantes sabios en la obra de Eusebio de Cesarea y Alcuino de York: la realeza sapiencial en la Antigüedad Tardía y la Alta Edad Media

915 Antonio SÁnchez González

El Archivo de los Mariscales de Castilla y Marqueses de Malagón

The Archives of the Marshals of Castile and the Marquises of Malagón

\section{Estudios y comentarios}

951 Serafín Olcoz Yanguas

Apostilla al estudio Influencia de las redes nobiliarias en la expansión cristiana del siglo XII: el caso de Soria (ETF, 33, 2020)

Notes on the Article The Influence of Aristocratic Networks on the Christian Expansion of the Twelfth Century. The Case of Soria $(E T F, 33,2020)$

\section{Libros $\cdot$ Books}

969 CASTRIllo CASAdo, Janire, Las mujeres vascas durante la Baja Edad Media (María Jesús Fuente)

973 Crónica del rey Juan II de Castilla. Minoría y primeros años de reinado (I406I420). Garcia, Michel (edición y estudio) (Víctor MuÑoz Gómez)

981 Da Silva, Marcelo Cândido, História Medieval (Diego Carlo Améndolla SPÍNOLA)

987 Galende Díaz, Juan Carlos y Ávila SeoAne, Nicolás, El rodado regio hispánico. Fernando III de León y Castilla (I23O-I252) (MAURicio Herrero JIMÉNEZ)

989 GARcía IzQuiERdo, Iván, Frontera, fuero y concejos. El valle del Riaza en la Edad Media (siglos VIII-XII) (CARLOS BARQUERO GOÑI)

993 García IzQuierdo, Iván y Peterson, David (coords.), Camino y Señorío. Obra selecta de Luis Martínez García (Enrique Cantera Montenegro) 
995 González Paz, Carlos Andrés, O Bispado de Mondoñedo na Idade Media. Territorio, comunidade e poder (ENRIQue CANTERA Montenegro)

997 López Martínez, Amalia, Minutarios notariales de Estevo Pérez (Ourense, siglo XIV) (José Miguel López Villalba)

999 Miranda García, Fermín y López de Guereño Sanz, María Teresa (eds.), La muerte de los príncipes en la Edad Media. Balance y perspectivas historiográficas (ANA Echevarría Arsuaga)

1003 Motis Dolader, Miguel Ángel, Vivencias, emociones y perfiles femeninos. Judeoconversas e Inquisición en Aragón en el siglo XV (ANA EcheVARRía ARSUAGA)

1007 Solórzano Telechea, Jesús Ángel y Martín Pérez, Fernando (coords.), Rutas de comunicación marítima y terrestre en los reinos hispánicos durante la Baja Edad Media. Movilidad, conectividad y gobernanza (ENRIQUe José Ruiz Pilares)

1013 Torre, Sandra de la - Etxeberria, Ekaitz - Díaz de Durana, José Ramón (coords.), Valer más en la tierra. Poder, violencia y linaje en el País Vasco bajomedieval (EnRIQue CANTERA Montenegro)

1015 TRIllo SAN José, Carmen, La Vega de Granada a partir de documentación árabe romanceada inédita (I457-I494). Estudio, edición e índices (INMACULADA GONZÁlez SopeÑA)

1019 Val Valdivieso, M. ${ }^{a}$ Isabel - Villanueva Zubizarreta, Olatz (Coords.), Pero Ansúrez. El conde, su época y su memoria (Enrique CANTERA Montenegro)

1021 Villanueva Morte, Concepción y Fernández de Córdova Miralles, Álvaro, El embajador Claver. Diplomacia y conflicto en las «Guerras de Italia» (I495-I504) (ENRIQUe CANTERA MONTENEGRO)

1023 Normas de publicación · Authors Guidelines 


\section{ESTUDIOS Y COMENTARIOS • STUDIES AND COMMENTS}





\title{
APOSTILLA AL ESTUDIO INFLUENCIA \\ DE LAS REDES NOBILIARIAS EN LA \\ EXPANSIÓN CRISTIANA DEL SIGLO XII: \\ EL CASO DE SORIA (ETF, 33, 2020)
}

\section{NOTES ON THE ARTICLE THE INFLUENCE OF ARISTOCRATIC NETWORKS ON THE CHRISTIAN EXPANSION OF THE TWELFTH CENTURY. THE CASE OF SORIA (ETF, 33, 2020)}

\author{
Serafín Olcoz Yanguas ${ }^{1}$
}

Recepción: 2020/09/10 · Comunicación de observaciones de evaluadores: 2020/12/03 . Aceptación: 2020/12/09

DOI: https://dx.doi.org/10.5944/etfiii.34.2021.28232

\section{Resumen}

Tras la lectura de un trabajo sobre los primeros tenentes de Soria, publicado en esta misma revista (ETF, 33, 2020), procedemos a corregir algunos de sus errores y a añadir algunas novedades sobre dichos nobles personajes, sus vínculos familiares y la influencia de éstos en la nueva Extremadura entre los reinos de Pamplona y Aragón, y de Castilla, así como sus relaciones con las Órdenes Militares y las cofradías seglares vinculadas a éstas, que también fueron clave en la evolución de dicho proceso.

\section{Palabras Clave}

Lehet; tenencia; Aragón; Pamplona; Soria; Órdenes Militares; Temple; cofradía.

\begin{abstract}
After reading the article on the first tenures (tenencias) of Soria, published in this same journal (ETF, 33, 2020), our aim is to rectify some of its errors and add some news about the noblemen who held these tenures. We will examine their family relationships and their influence in the new Extremadura between the kingdoms of Pamplona and Aragon, and that of Castile, as well as its relations with the
\end{abstract}

1. Doctor en Historia Antigua (Universidad de Zaragoza). C.e.: solcoz@gmail.com 
Military Orders and the secular brotherhoods linked to them, which were also central to the evolution of this process.

\section{Keywords}

Lehet; Land Tenures; Aragon; Pamplona; Soria; Military Order; Templars; Brotherhood. 


\section{INTRODUCCIÓN}

Recientemente, Soriano publicó en esta misma revista un trabajo cuyo objetivo era: «estudiar el fenómeno a través del caso concreto de la familia navarra Lehet y su relación con los dos primeros señores de Soria, Înigo López y Fortún López.»². Aunque, en realidad, dicho trabajo se centraba específicamente en la identificación genealógica y biográfica de dichos tenentes.

En dicho trabajo y en otros que también citamos, aunque principalmente nos centraremos en revisar el de Soriano, se incluyeron algunos errores que hemos creído necesario corregir, en aras de quienes puedan estar interesados en dichos tenentes o en cómo se inició la reconquista en Soria y en cómo influyeron en ésta las redes nobiliarias. Aunque también debemos reconocer que en dicho trabajo se hicieron algunas aportaciones interesantes, que también destacamos y revisaremos a continuación. Pues nuestro objetivo es el de mejorar el conocimiento existente acerca de las citadas redes nobiliarias y de cada uno de sus miembros, no sólo por su valor intrínseco, sino porque su conocimiento también permitirá entender mejor el contexto de los diplomas coetáneos en los que figuran estos nobles e incluso también ayudará a distinguir algunas falsificaciones, concretamente a las que se podrán detectar debido a los fallos cometidos por los escribas sin escrúpulos que interpolaron o falsificaron algunos de esos documentos y que, hasta ahora y debido al desconocimiento generalizado que existe acerca de la mayoría de los magnates que figuran como testigos o a los que se les cita en las cláusulas de dichos documentos, no ha sido posible ponerlas en evidencia.

Finalmente, queremos señalar que, al revisar las relaciones familiares de los dos primeros tenentes de Soria y de sus descendientes, veremos que la influencia de las redes nobiliarias en la expansión cristiana del siglo XII es mucho más compleja y abundante de lo que a primera vista podría parecer.

\section{EL SOLAR ORIGINARIO DE LA CASA DE LEHET}

Los dos primeros tenentes de Soria fueron dos hermanos, que estuvieron casados con dos hermanas pertenecientes a la Casa de Lehet, como veremos más adelante, de ahí que Soriano trajera a colación este linaje al tratar acerca del de aquéllos³.

2. Cfr. Soriano Calvo, Gilberto. «Influencia de las redes nobiliarias en la expansión cristiana del siglo xII. El caso de Soria». Espacio, tiempo y forma. Serie III, Historia medieval, n. 33, 2020, pp. 579-612.

3. Cfr. Soriano Calvo, Gilberto. «Influencia de las redes nobiliarias en la expansión cristiana del siglo xII. El caso de Soria». Op. cit., pp. 588-589, 594-595, 597, 601-603 y 605, supuso que Î̃nigo y Fortún López prosperaron gracias a sus relaciones con la Casa de Lehet. Así como que el segundo matrimonio de Fortún López le desvinculó de dicho linaje y lo acercó al de los Lara, alineando sus intereses con los de Castilla. Una visión que es muy simplista y que no tiene en cuenta las complejas y abundantes relaciones entre las familias nobles de la época, como veremos más adelante. 
Basándose en Jaurgain ${ }^{4}$, Soriano identificó el solar originario de la Casa de Lehet en el sur del actual sur de Francia, en Sare (Aquitania), o sea, poco después de cruzar la actual frontera de Navarra por el puerto de Dancharinea. Una identificación que carece de base alguna y que, además, hace ya muchas décadas que había sido corregida, localizando correctamente el solar originario de la Casa de Lehet en Lete, en la actual cendea de lza (Navarra) 5 . Por lo que sorprende que se hubiera obviado la información recogida en la historiografía más reciente, para recuperar una propuesta errónea y desfasada.

En cualquier caso, Soriano también propuso que el padre de Jimeno Fortuñones de Lehet debió de haber sido el Fortún Sánchez que fue tenente de Huarte (Navarra) y de Peralta (Navarra) ${ }^{6}$. Una propuesta que coincide con la que previamente había realizado Fortún, identificando al Fortún de Lehet que usaba el sobrenombre de Dodo, con el padre de Jimeno Fortuñones de Lehet ${ }^{7}$, que fue el primero de este linaje que añadió a su apellido el topónimo de Lehet $^{8}$. Además, hemos de señalar que, aunque Soriano no tuvo en cuenta que la esposa de éste fue Toda de Lehet, que es con quien tuvo a Martín, María y Sancha de Lehet $^{9}$, ni tampoco reconoció a esta última como hija de dicho matrimonio, sí que añadió que los hermanos de Jimeno Fortuñones fueron García y Sancho Fortuñones. Todo ello sin tener en cuenta que este último ya había sido identificado por Fortún ${ }^{\text {Io }}$.

4. Cfr. JaURGAIN, Jean de, «Toponymie basque», en Eusko ikaskuntzen nazioarteko aldizkaria / Revue internationale des études basques / International journal on Basque studies, volumen 6, número 2, 1914, p. 163.

5. Cfr. Martín DuQue, Ángel. Documentación medieval de Leire (siglos IX a XII). Pamplona: Gobierno de Navarra, 1983, p. 531, Fortún Pérez de Ciriza, Luis Javier. Sancho VIl el Fuerte (1194-1234). Iruña: Mintzoa, 1986, p. 111, PAVóN BENITO, Julia. Poblamiento altomedieval navarro: base socioeconómica del espacio monárquico. Pamplona: EUNSA, 2000, p. 114, Mugueta Moreno, İnigo. «La nobleza en Navarra (siglos XIII-XIV): Una identidad militar». lura vasconiae, n. 4, 2007, p. 206, y Remírez Vallejo, Salvador. «Mulieres Templi. Cofradesas y donadas del Temple en el reino de Navarra (siglo XII)». Príncipe de Viana, n. 273, 2019, p. 108. Además, el propio SORIANo CaLvo, Gilberto. «Influencia de las redes nobiliarias en la expansión cristiana del siglo XII. El caso de Soria». Op. cit., p. 587, señaló que «los intereses territoriales de los Lehet fueron extendiéndose hacia el sur, desde Pamplona hacia la zona norte de Tudela y este de Calahorra», algo que coincide con el hecho de que su solar originario estuviera en las cercanías de Pamplona y, para nada, con que fuera ultrapirenáico.

6. Cfr. Soriano Calvo, Gilberto. «Influencia de las redes nobiliarias en la expansión cristiana del siglo xII. El caso de Soria». Op. cit., pp. 585-586. Jimeno Fortuñones sucedió a Fortún Sánchez en Huarte y en Peralta, como recogió UbIETo ArtetA, Agustín. Los tenentes de Aragón y Navarra en los siglos XI y XII. Valencia: Anubar, 1973, pp. 142, 153, 212-213 y 237. Aunque éste creyó erróneamente que el Fortún Sánchez que fue tenente de Huarte fue distinto del homónimo que lo fue de Peralta, al no tener en cuenta que figura simultáneamente en ambas tenencias, como señaló Soriano.

7. Cfr. Fortún Pérez de CirizA, Luis Javier. Sancho vil el Fuerte (1194-1234). Op. cit., p. 111.

8. Cfr. Remírez Vallejo, Salvador. «Mulieres Templi. Cofradesas y donadas del Temple en el reino de Navarra (siglo XII)». Op. cit., p. 108.

9. Cfr. Olcoz Yanguas, Serafín. «Iinigo y Fortún López: los dos primeros tenentes de Soria, durante el reinado de Alfonso I de Aragón y Pamplona». Berceo, n. 174, 2018, pp. 282-283, y Remírez VALLejO, Salvador. «Mulieres Templi. Cofradesas y donadas del Temple en el reino de Navarra (siglo XII)». Op. cit., p. 108. Así como, SorIANo Calvo, Gilberto. «Influencia de las redes nobiliarias en la expansión cristiana del siglo XII. El caso de Soria». Op. cit., p. 600.

10. Cfr. Fortún Pérez de Ciriza, Luis Javier. Sancho vil el Fuerte (1194-1234). Op. cit., p. 111. 


\section{LA POBLACIÓN DE SORIA}

Al tratar acerca de los dos primeros tenentes de Soria, Soriano consideró que la población de Soria se produjo entre IIo9 y III9 ${ }^{\text {II }}$, a pesar de haber citado ${ }^{\text {I2 }}$ que, según los Anales Compostelanos: «Era MCLVII. Populavit Rex Aldefonsus ${ }^{13}$ Soriam» ${ }^{14}$ y de insistir después en que este monarca poco tuvo que ver con Soria ${ }^{15}$. Una cita compostelana que Corral también tuvo en cuenta, a pesar de que prefirió considerar que Alfonso I ocupó Soria, entre mediados de iıı7 y los primeros meses de III8, así como que procedió a su repoblación entre la segunda mitad de inig y la primavera de $\mathrm{II} \mathrm{O}^{\mathrm{I}}{ }^{6}$. Sin embargo, debemos señalar que no hay ningún resto arqueológico ni tampoco ninguna noticia documental que sea fiable y que también sea anterior a III9, en la que figure Soria o el lugar en el que se encuentra esta localidad, en caso de que previamente hubiera sido conocido por otro nombre, y que mientras no se conozca ninguna fuente que así lo acredite, creemos que lo más adecuado es considerar que Soria fue poblada o que, al menos, fue repoblada entonces, o sea, en inig, y que fue el rey de Aragón y Pamplona ${ }^{17}$, Alfonso I, quien se encargó de que así se hiciera.

De hecho, en I243, el arzobispo Rodrigo Ximénez de Rada expresó claramente que fue Alfonso I quien reconquistó el territorio musulmán en el que se encontraba

11. Cfr. Soriano Calvo, Gilberto. «De la fundación o población de Soria». En De la Casa Martínez, Carlos y Martín Marco, José Antonio (Coord.), Soria 1119, Soria: Ayuntamiento de Soria, 2019, pp. 35-36 y 38-39.

12. Cfr. Soriano Calvo, Gilberto, «De la fundación o población de Soria», Op. cit., p. 12.

13. Martínez Díez, Gonzalo. «El Fuero de Soria: Génesis y fuentes», Anuario de historia del derecho español, n. 76, 2006, p. 11, identificó al rey Alfonso con el de Aragón y Pamplona, Alfonso Sánchez, como el repoblador de Soria.

14. Annales compostellani o Tumbo Negro, contenido en el Apéndice vi de Flórez de SetiÉn Huidobro, Enrique. España Sagrada Theatro Geographico-historico de la I glesia de España. Tomo xxIII. Continuacion de las memorias de la Santa Iglesia de Tuy. Y coleccion de los cronicones pequeños publicados e ineditos, de la Historia de España. Madrid: Antonio Marin, 1777 , p. 321. Estos anales contienen información hasta 1248, por lo que tuvieron que ser elaborados después de esta fecha.

15. Cfr. Soriano Calvo, Gilberto. «Influencia de las redes nobiliarias en la expansión cristiana del siglo xII. El caso de Soria». Op. cit., pp. 602-605, tras haber reconocido que Alfonso I fue el poblador de Soria y quien nombró a los dos tenentes que esta estratégica localidad tuvo durante el reinado de aquél, por su posición fronteriza con la cercana Castilla, como acertadamente había señalado AsEnjo GonzÁLEZ, María. «lnstituciones: poder, sociedad, gobierno y vecindad en Soria (siglos XII al XIV). De las collaciones a las cuadrillas». En De la Casa Martínez, Carlos y Martín Marco, José Antonio (Coord.), Soria 1119, Soria: Ayuntamiento de Soria, 2019, pp. 305-311, contradijo a ésta y, frente a lo acaecido en esta época y a lo recogido en la documentación, procedió a quitarle importancia y a minimizar el claro interés que demostró Alfonso I por su tenencia de Soria.

16. Cfr. Corral Lafuente, José Luis. «Alfonso I el Batallador, la ciudad de Soria y su territorio». En De la Casa Martínez, Carlos y Martín Marco, José Antonio (Coord.), Soria 1119, Soria: Ayuntamiento de Soria, 2019, pp. $97-98$ y 100. Quizá porque dio por bueno un documento de 1117, en el que Î́nigo López figura como tenente de Soria, a pesar de que el mismo Corral señaló que su fiabilidad estaba en entredicho, como ya había expuesto Lema PuEYo, José Ángel. Colección diplomática de Alfonso I de Aragón y Pamplona (1104-1134). San Sebastián: Sociedad de Estudios Vascos, 1990, n. 82, pp. 123-128. Además, creyó que, durante este tiempo, Alfonso I estuvo en Soria, a pesar de que la documentación lo desmiente, como recogió Lema PueYo, José Ángel. «El itinerario de Alfonso I 'El batallador' (1104-1134)». Historia. Instituciones. Documentos, n. 24, 1997, p. 345, y como el propio Corral señaló más adelante, indicando que dicho rey estuvo en Pedraza (Segovia), el 13 de diciembre de 1119, Lema Pueyo, José Ángel. Colección diplomática de Alfonso I de Aragón y Pamplona (1104-1134), Op. cit., n. 95, pp. 149-152.

17. Cfr. Soriano Calvo, Gilberto, «De la fundación o población de Soria», Op. cit., citó en varias ocasiones a Alfonso I como rey de Aragón y Navarra, una intitulación que no figura así en ninguno de los documentos de su cancillería ni de su época, por lo que es extemporánea. Un error que, de alguna manera, señaló el propio SoRIANo CaLvo, Gilberto, «Influencia de las redes nobiliarias en la expansión cristiana del siglo XII. El caso de Soria», Op. cit, p. 581, aunque sin enmendarse, ya que siguió insistiendo en utilizar dicha denominación extemporánea para referirse al reino de Pamplona. 
Soria y que, cuando así lo hizo, éste estaba desierto ${ }^{\mathrm{I} 8}$. También recogió que, cuando Alfonso I repudió a Urraca, la acompañó hasta Soria ${ }^{\text {I9 }}$, aunque esta mención también se podría interpretar como una referencia al lugar donde años después estuvo Soria y no necesariamente a esta localidad. No obstante, parece ser que, en esta ocasión, la información recogida por dicho arzobispo no fue muy precisa, pues ya señaló Corral que era más fiable la existente en la Primera Crónica Anónima de Sahagún (León), que sitúa en Astorga (León) el lugar en el que Alfonso I repudió a Urraca ${ }^{20}$. Por lo que creemos que Alfonso I fue quien repobló o, con mayor probabilidad y como ya había propuesto Almazán ${ }^{21}$, pobló Soria en III9, y, en cualquier caso, parece que no hay duda de que la referencia documental más antigua de Soria es la que consta durante el asedio de Tarazona (Zaragoza) ${ }^{22}$.

\section{ÍÑIGO LÓPEZ}

Soriano expuso como si fueran suyas la mayoría de las conclusiones a las que habíamos llegado en el mencionado trabajo sobre los dos primeros tenentes de Soria. Bien es verdad que aquél, además, realizó algunas propuestas, aunque con dudoso acierto, como vamos a ver a continuación.

Por una parte, negó la identificación del primer tenente de Soria con el homónimo Íñigo López que consta como mayordomo de Alfonso I, en $\mathrm{II}_{2} \mathrm{O}^{23}$, sin aportar prueba

18. Así lo recogió también el propio arzobispo Ximénez de Rada, escribiendo: «ldem etiam Rex [Alfonso I] habens Urracam filiam Regis Aldefonsi [VIII] qui cepit Toletum, populavit Soriam, Almazan [(Soria)], Valeranicam, quæ nunc Verlanga [Berlanga de Duero (Soria)] dicitur, et Belliforamen [Belorado (Burgos)].», aclarando que Alfonso I halló desiertos estos lugares, cuando los reconquistó del dominio musulmán, escribiendo que «Verum Rex Aragonum Aldefonsus... et a Maurorum incursibus viriliter custodivit, et regnum Castellæ tamquam proprium undique dilatavit: et loca deserta restituens, ductis incolis populavit, videlicet Belliforamen, Valeranicam, Soriam, Almazanam.», CABANES PECOURT, Má. Desamparados. Rodericus Ximenius de Rada: Opera. Zaragoza: Anubar, pp. 85 y 147.

19. «Sed tempore procedente, cum Rex intellexisset a suis beneplacitis alienam, Soriam usque eam duxit, ibique repudians, dimisit eam suæ arbitrio voluntatis, et ipsa ad Comitem Petrum Assurii properans, suo consilio se commisit.», CABANES Pecourt, Ma . Desamparados. Rodericus Ximenius de Rada: Opera. Op. cit., p. 148.

20. Cfr. Corral Lafuente, José Luis. «Alfonso I el Batallador, la ciudad de Soria y su territorio», Op. cit., pp. 94-95. A pesar de que la Primera Crónica Anónima nos ha llegado a través de una versión que data del siglo XV, su información parece corresponder con los acontecimientos acaecidos a principios del siglo XII.

21. Cfr. Olcoz Yanguas, Serafín. «Iñigo y Fortún López: los dos primeros tenentes de Soria, durante el reinado de Alfonso I de Aragón y Pamplona», Op. cit., p. 269.

22. Cfr. Olcoz Yanguas, Serafín. «Iñigo y Fortún López: los dos primeros tenentes de Soria, durante el reinado de Alfonso I de Aragón y Pamplona», Op. cit., p. 269, y Los orígenes del Temple en el valle medio de Ebro: Antecedentes de la Orden del Cister y de la Orden Militar de Calatrava. Tudela: Ayuntamiento de Fitero, 2019, pp. 37-39, consideró que el asedio de Tarazona se prolongó hasta finales de 1119 e incluso hasta principios de 1120, antes de mazo. Mientras que SORIANO CALVO, Gilberto. «Influencia de las redes nobiliarias en la expansión cristiana del siglo XII. El caso de Soria». Op. cit., p. 589, también lo creyó así, aunque consideró que dicha referencia documental podía tratar de marzo de 1119, siguiendo a CANELLAS LóPEZ, Ángel (1963-1965). «Tarazona y sus gentes en el siglo XII». Cuadernos de historia, Jerónimo Zurita, n. 16-18, pp. 28-29. Algo que es difícil de creer pues Alfonso I, tras reconquistar Tudela, el 25 de febrero de 1119 , tuvo que haberse desplazado hasta Soria, nombrando allí a su primer tenente y dejando organizada esta parte del territorio, antes de proceder a iniciar el asedio de Tarazona, en el que ya figura el primer tenente de Soria.

23. Soriano Calvo, Gilberto. «Influencia de las redes nobiliarias en la expansión cristiana del siglo XII. El caso de Soria». Op. cit., p. 589. 
alguna para ello y sin señalar que, tanto Olcoz como Corral e incluso Nuño ${ }^{24}$, sí que habían propuesto tal identificación y su vinculación con los documentos relacionados con Soria. Por otra parte, Soriano consideró que el primer tenente de Soria debió de haber sido nieto del homónimo İñigo López que fue señor de Vizcaya ${ }^{25}$. Igualmente lo propuso sin aportar ninguna prueba y sin citar que Corral había planteado identificar al Íñigo López que fue tenente de Soria con el homónimo que lo había sido en el somontano del Prepirineo, en los primeros años del reinado de Alfonso I, así como a Fortún López lo había identificado con el que, en enero de II25, era tenente en Ayerbe (Huesca) ${ }^{26}$, aunque también sin apuntar más base para esta propuesta que la de la mera coincidente homonimia de ambos tenentes. Además, y sin presentar ningún argumento o documento en el que basarse, Corral también propuso que Íñigo López era de origen navarro, concretamente, hijo del magnate Înigo García de Estella (Navarra) ${ }^{27}$. Una afirmación que es difícil de mantener, ya que no respeta las reglas patronímicas de la época, ni tampoco fue acompañada con ningún motivo que pudiera justificar esta posible excepción.

En cualquier caso y poco después, Olcoz ${ }^{28}$ aclaró el linaje del que descendía el primer tenente de Soria, que nada tiene que ver con la propuesta de Corral, aunque algo sí que está relacionado con la propuesta de Soriano, ya que, aunque este Íñigo López no fue nieto del homónimo conde l̂nigo López que fue señor de Llodio, sí que fue el bisnieto de un hermano de éste, o sea, bisnieto de Sancho Lopez. Como puede verse en el árbol genealógico correspondiente al linaje de los Vela y sus relaciones con el de Lehet y el de Haro (Figura I).

Finalmente, Soriano, sin plantearse que hubo más de un Lope López coetáneo ${ }^{29}$, llegó a la conclusión de que uno de estos tenentes homónimos, nada había tenido

24. Cfr. Olcoz Yanguas, Serafín. «Ĩ̃ingo y Fortún López: los dos primeros tenentes de Soria, durante el reinado de Alfonso I de Aragón y Pamplona», Op. cit., p. 271, y CoRRAL LAFUenTE, José Luis. «Alfonso I el Batallador, la ciudad de Soria y su territorio», Op. cit., p. 102, basándose en LemA PueYo, José Ángel. Colección diplomática de Alfonso I de Aragón y Pamplona (1104-1134), Op. cit., n. 103, pp. 158-159. También lo hizo así NuÑo GonzÁLEZ, Jaime. «La repoblación de la ciudad de Soria: cuestiones de geografía y topografía». En De la Casa Martínez, Carlos y Martín Marco, José Antonio (Coord.), Soria 1119, Soria: Ayuntamiento de Soria, 2019, p. 184. Si bien Corral y Nuño parece que desconocían el trabajo de Olcoz, pues no lo citaron.

25. Soriano Calvo, Gilberto. «De la fundación o población de Soria». Op. cit., pp. 36-38 e «Influencia de las redes nobiliarias en la expansión cristiana del siglo xIl. El caso de Soria», Op. cit., p. 589.

26. Cfr. Corral Lafuente, José Luis. «Alfonso I el Batallador, la ciudad de Soria y su territorio», Op. cit., (pp. 102-103). También recogió que Fortún López fue tenente de Burgos, Mendigorría (Navarra), San Esteban de Gormaz (Soria), Milagro (Navarra) y Yanguas (Soria), p. 104.

27. Cfr. Corral Lafuente, José Luis. «Alfonso I el Batallador, la ciudad de Soria y su territorio», Op. cit., pp. 101-102.

28. Cfr. Olcoz Yanguas, Serafín. Los orígenes del Temple en el valle medio de Ebro: Antecedentes de la Orden del Cister y de la Orden Militar de Calatrava. Tudela: Ayuntamiento de Fitero, 2019, pp. 35-39 y 64. Si bien cometió un lapsus al representar el árbol genealógico (figuras 4 y 6), confundiendo a Jimeno Aznárez con su homónimo nieto, el cofrade templario Jimeno Aznárez de Torres, así como a la hija de aquél Auria Jiménez con la segunda esposa de Ínigo Vélaz, cuando fue la única esposa de éste. Lapsus que, como el de haber confundido a Lope de Mendoza con su homónimo tío, Lope Iñiguez de Mendoza, que fue señor de Llodio (Álava) y que estuvo casado con Teresa Jiménez, como ya había expuesto el propio OLCOZ YANGUAS, Serafín. «Ĩ̃igo y Fortún López: los dos primeros tenentes de Soria, durante el reinado de Alfonso I de Aragón y Pamplona», Op. cit., p. 283, corregimos en el árbol genealógico que presentamos a continuación y en el que añadimos a los citados hermanos de Jimeno Fortuñones de Lehet.

29. Cfr. Olcoz Yanguas, Serafín. «Cuatro Lope López en el reino de Aragón y Pamplona: el origen del linaje Almoravid, y sus relaciones con Liédena, Calahorra y otras tenencias del valle del río Ebro. Kalakorikos, n. 23, 2018, 
que ver con el Íñigo López que fue primer tenente de Soria. Aunque como su argumentación fue tan superficial como sintética, poco más podemos decir acerca de sus conclusiones al respecto, salvo que veremos que eran erróneas y que sí que hubo una relación de parentesco entre el primer tenente de Soria, Iñigo López, y su padre, Lope López de Mendoza (Álava).

\section{FORTÚN LÓPEZ}

Olcoz propuso que Fortún e ĺñigo López fueron hermanos, tal y como poco después hizo Remírez, basándose en los mismos argumentos ${ }^{30}$, y como más tarde también intuyeron Corral y Soriano, aunque éstos lo hicieron sin aportar ningún fundamento para ello ${ }^{31}$. Si bien este último, además, señaló que dichos hermanos no tuvieron ninguna relación con el Lope Iñiguez que se casó con la viuda de liñigo López, cuando hemos visto que estos hermanos López fueron primos de este Lope Iñiguez.

Soriano también recogió la información relativa a que el alcaide del castillo de Soria, Fortún Garcés, fue cuñado de Fortún López, por haber estado casado con la hermana de éste, Urraca, tal y como ya había expuesto Olcoz ${ }^{32}$. No obstante, Soriano aportó la noticia de que el maestre de Calatrava, frey Rodrigo Garcés, fue hijo de García Garcés de Aza ${ }^{33}$, que, a su vez, fue hijo del conde García Ordóñez ${ }^{34}$, y de Leonor Fortuñones, que fue hija de Fortún López de Soria y de Elvira Pérez, que, a su vez, fue hija de Pedro Núñez de Fuentearmegil35, según había publicado Rades ${ }^{36}$. Aunque

pp. 243-265, identificó cuatro tenentes homónimos y coetáneos. A estos cuatro Lope López, hay que añadir los Lope López de Mendoza que también identificó Olcoz Yanguas, Serafín. Los orígenes del Temple en el valle medio de Ebro: Antecedentes de la Orden del Cister y de la Orden Militar de Calatrava. Op. cit., pp. 34-35, como hemos visto en el primer árbol genealógico.

30. Cfr. Olcoz Yanguas, Serafín. «Ĩnigo y Fortún López: los dos primeros tenentes de Soria, durante el reinado de Alfonso I de Aragón y Pamplona», Op. cit., p. 283, y RemíRez VALLEjo, Salvador. «Mulieres Templi. Cofradesas y donadas del Temple en el reino de Navarra (siglo XII)». Op. cit., pp. 109-112.

31. Cfr. Corral Lafuente, José Luis. «Alfonso I el Batallador, la ciudad de Soria y su territorio». En De la Casa Martínez, Carlos y Martín Marco, José Antonio (Coord.), Soria 1119, Soria: Ayuntamiento de Soria, 2019, pp. 101-102, y SorIANo Calvo, Gilberto. «Influencia de las redes nobiliarias en la expansión cristiana del siglo XII. El caso de Soria». Op. cit., pp. 595-596 y 600-601.

32. Cfr. Olcoz Yanguas, Serafín. «Ĩñigo y Fortún López: los dos primeros tenentes de Soria, durante el reinado de Alfonso I de Aragón y Pamplona», Op. cit., p. 284, y SoRIANo CaLvo, Gilberto. «Influencia de las redes nobiliarias en la expansión cristiana del siglo XII. El caso de Soria», Op. cit., p. 600.

33. Haza (Burgos).

34. Cfr. Salazar Acha, Jaime. «El linaje castellano de Castro en el siglo XII: consideraciones e hipótesis sobre su origen». Anales de la Real Academia Matritense de Heráldica y Genealogía, n. 1, 1991, p. 54, recogió la noticia de que el conde García Ordoñez se casó, en segundas nupcias, con Eva, quien, tras la muerte de aquél, se casó con Pedro González de Lara (Lara de los Infantes, Burgos), y también corrigió la creencia de que ésta fue hija del conde Pedro Froliaz de Traba (Santiago de Traba, La Coruña), decantándose por que lo fue de Almarico II, vizconde de Rochechouart (Francia).

35. Fuentearmegil (El Burgo de Osma, Soria). Cfr. GonzÁlez GonzÁlez, Julio. El reino de Castilla en la época de Alfonso vIII. Tomo I: Estudio. Madrid: Consejo Superior de Investigaciones Científicas. 1960, pp. 270-271, recogió que Elvira Pérez fue hija de Pedro Núñez de Fuentearmegil y de Elvira González de Lara, hermana de Pedro González de Lara.

36. Cfr. Rades Andrada, Francisco. Chronica de las tres Ordenes y Cauallerias de Sanctiago, Calatraua y Alcántara: en la qual se trata de su origen y sucesso, y notables hechos en armas de los Maestres y Caualleros de ellas: y de muchos Señores de Titulo y otros Nobles que descienden de los Maestres: y de muchos Linages de España. Compuesta por el Licenciado Frey Francisco de Rades y Andrada, Capellan de su Magestad, de la Orden de Calatraua. Dirigida a la C.R.M. del Rey don 
Soriano dejó abierta la posibilidad de que el padre de Leonor Fortuñones, en vez de haber sido Fortún López de Soria, hubiera sido un supuesto homónimo nieto de éste, tal y como había dado a entender Rades ${ }^{37}$. Sin embargo, no hay noticias de la existencia de este nieto entre los que tuvo Fortún López de Soria, como podemos ver en el árbol genealógico del Linaje de Lope de Cintruénigo ${ }^{38}$ (Figura 2).

Por lo que, en caso de que la información genealógica facilitada por Rades sea correcta y tal y como ya propusiera Soriano, podemos considerar que, tras enviudar de Sancha de Lehet, Fortún López de Soria debió de haber vuelto a casarse con Elvira Pérez, sobrina de Pedro y de Rodrigo González de Lara, que también fue cofrade templario ${ }^{39}$, con quien tuvo al que fue maestre de Calatrava, desde la propia batalla de Las Navas de Tolosa (Jaén), el I6 de julio de I2I2, hasta I2I6: frey Rodrigo Garcés ${ }^{40}$. Siendo ésta, precisamente, la única información que Soriano pudo recabar acerca de los vínculos familiares de Fortún López.

Por otra parte, hay constancia de que García García de Aza estuvo casado con Sancha Pérez, con quien tuvo a Pedro, Gómez, Ordoño, García y Gonzalo, así como a Mayor, María, Sancha y Elvira ${ }^{41}$. Por lo que, de ser cierta la información publicada por Rades, Leonor Fortuñones habría sido la segunda esposa de García García de Aza y podríamos añadir este segundo matrimonio al árbol genealógico de su linaje ${ }^{42}$ (Figura 3).

Finalmente, debemos señalar que Soriano también se hizo eco de la noticia publicada por Rades, acerca de que durante el maestrazgo de frey Fernando Escaza, al frente de la Orden Militar de Calatrava, o sea, entre II69 y II70 ${ }^{43}$, Fortún López de Soria ingresó como familiar de dicha Orden, donando la iglesia de San Salvador (Soria), que él había fundado y que después pasó a convertirse en la sede de una

Philippe nuestro señor, Administrador perpetuo destas Ordenes. Toledo: Casa de Juan Ayala, 1572, Crónica de Calatrava, f. 31r. Además, recogió que Pedro Núñez de Fuentearmegil fue hermano de Fernando Núñez, que había recibido los hábitos templarios, aunque falleció con los de Calatrava, y que ambos fueron hijos de Nuño Garcés de Fuentearmegil y de Teresa Fernández, cfr. Rades Andrada, Francisco. Chronica de las tres Ordenes ... Op. cit., Crónica de Calatrava, f. 16v.

37. Cfr. Rades Andrada, Francisco. Chronica de las tres Ordenes ... Op. cit., Crónica de Calatrava, f. 17r.

38. Cfr. Olcoz Yanguas, Serafín. Los orígenes del Temple en el valle medio de Ebro: Antecedentes de la Orden del Cistery de la Orden Militar de Calatrava. Op. cit., pp. 62-68.

39. Cfr. Olcoz YAnguas, Serafín. Los orígenes del Temple en el valle medio de Ebro: Antecedentes de la Orden del Cistery de la Orden Militar de Calatrava. Op. cit., pp. 51-54.

40. Cfr. Rades Andrada, Francisco. Chronica de las tres Ordenes ... Op. cit., Crónica de Calatrava, ff. 3ov-3zr. Además, añadió que frey Rodrigo Garcés tuvo tres hijos, sin que se sepa si fueron fruto de un matrimonio previo a profesar como caballero de Calatrava o si fueron ilegítimos: Gómez Ruiz, que fue caballero de Santiago, Fernando Ruiz, que fue ciego y que se casó en Ágreda, y Leonor Ruiz de Aza, que se casó con Gil de Roa y que, tras enviudar, ingresó en el monasterio de Santa Eufemia de Cozollos (Olmos de Ojeda, Palencia), que perteneció a la Orden Militar de Santiago, Cfr. FerrerVidal díaz Del Reguero, María Soledad. Santa Eufemia de Cozuelos: un monasterio femenino de la Orden Militar de Santiago. En la España Medieval (Ejemplar dedicado a: En memoria de Salvador de Moxó (I)), n. 2, 1982, pp. 337-348.

41. Cfr. García IzQuierdo, Iván. «El linaje de Aza. Origen, evolución e impacto de una familia aristocrática en la Castilla suroriental». Studia histórica. Historia medieval, v. 35, n. 1, pp. 143.

42. Añadimos también el dato de que, en 1248, Pedro Martínez de Lehet fue comendador de la Orden de San Juan de Jerusalén, en la encomienda de Leache (Navarra). Cfr. PAvón BENITO, Julia. «La encomienda sanjuanista de Leache en la Edad Media. Una primera aproximación». Príncipe de Viana, (Ejemplar dedicado a: vII Congreso General de Historia de Navarra (Vol. 1)), n. 253, 2011, p. 286.

43. Cfr. Rades Andrada, Francisco. Chronica de las tres Ordenes ... Op. cit., Crónica de Calatrava, ff. 14v-17r y 22 r. 
encomienda de la Orden Militar de Calatrava ${ }^{44}$. Algo que Fortún López de Soria debió de realizar estando próximo a su muerte, pues ésta sería la última noticia conocida acerca del segundo tenente de Soria.

\section{CONCLUSIONES}

Tal y como era nuestro propósito, hemos abundado en los vínculos familiares de los dos primeros tenentes de Soria: Iñigo y Fortún López, corrigiendo algunos errores acerca de su identificación genealógica y ampliando la información relativa a los vínculos familiares con varios linajes nobiliarios. También hemos visto que eran mucho más complejas y abundantes de lo que se creía, así como hemos visto que, aunque éstas debieron influir en el posicionamiento de sus miembros en puestos destacados de la jerarquía gobernante, no fueron estos lazos de sangre los únicos que debieron contribuir a ello. De hecho, hemos visto que buena parte de los nobles que hemos citado y que desempeñaron una labor destacada en la reconquista de la taifa de Zaragoza, que llevó a cabo Alfonso I de Aragón y Pamplona, tuvieron también en común su pertenencia a la cofradía del Temple. Por lo que debemos identificar a los vínculos de pertenencia a esta cofradía, que iban más allá de su natural carácter religioso, como un destacado complemento a los vínculos de sangre que unieron a los linajes nobiliarios involucrados en la reconquista. Unos vínculos complementarios a los sanguíneos que son similares a los que después y hasta la caída del Antiguo Régimen, desempeñó la pertenencia a las Órdenes Militares de carácter exclusivamente hispano, como las citadas de Calatrava y de Santiago, pero no nos referimos sólo a los vínculos de aquellos miembros de los linajes nobiliarios que profesaron como freires en dichas Órdenes Militares, sino que también queremos destacar la pertenencia de sus familiares como miembros seglares de dichas instituciones de carácter religiosomilitar y también político. Pues la pertenencia a estas cofradías seglares o sus vínculos como familiares de las Órdenes Militares suponía, de hecho, la participación en algo similar a lo que actualmente consideramos como Lobbies, esto es, como organizaciones que, de forma más o menos solapada, influían e influyen en la vida política y económica. De modo que su estudio y conocimiento puede y podríamos añadir que debe convertirse en una fuente de información complementaria para entender mejor las relaciones que se dieron entre los nobles que participaron en el proceso de la reconquista. Al menos, a partir de la aparición de dichas cofradías y Órdenes Militares en el siglo XII.

44. Cfr. Rodríguez-Picavea Matilla, Enrique. La formación del feudalismo en la meseta meridional castellana: Los señoríos de la Orden de Calatrava en los siglos XII-XIII. Madrid: Siglo Veintiuno, 1994, p. 152, recogió que la iglesia de San Salvador de Soria fue sede de una encomienda calatrava y que su primer comendador fue frey Alonso López de Haro, durante el maestrazgo de Nuño Pérez de Quiñones, o sea, entre 1182 y 1198, según recogió RADES ANDRADA, Francisco. Chronica de las tres Ordenes ... Op. cit., Crónica de Calatrava, f. 22r. 


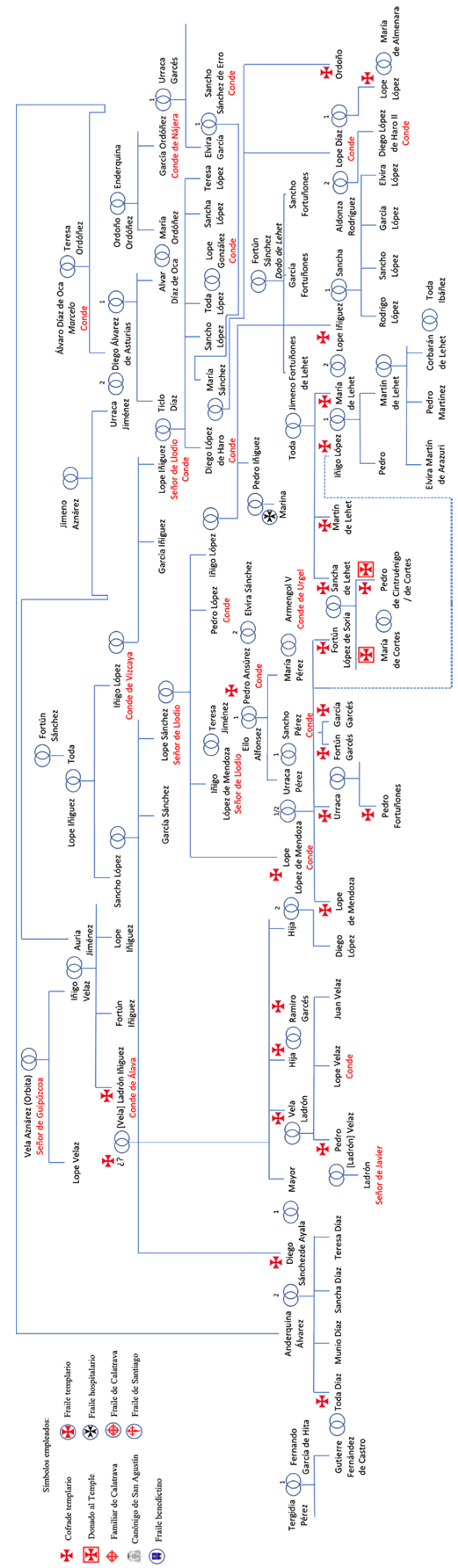

FIGURA 1. LINAJE DE LOS VELA Y SUS RELACIONES CON EL DE LEHET Y EL DE HARO 


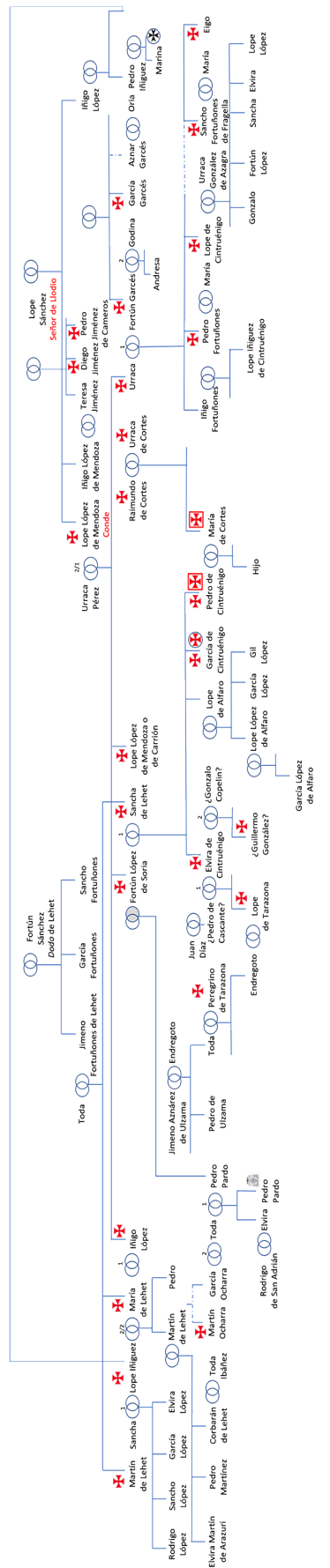

FIGURA 2. LINAJE DE LOPE DE CINTRUÉNIGO 


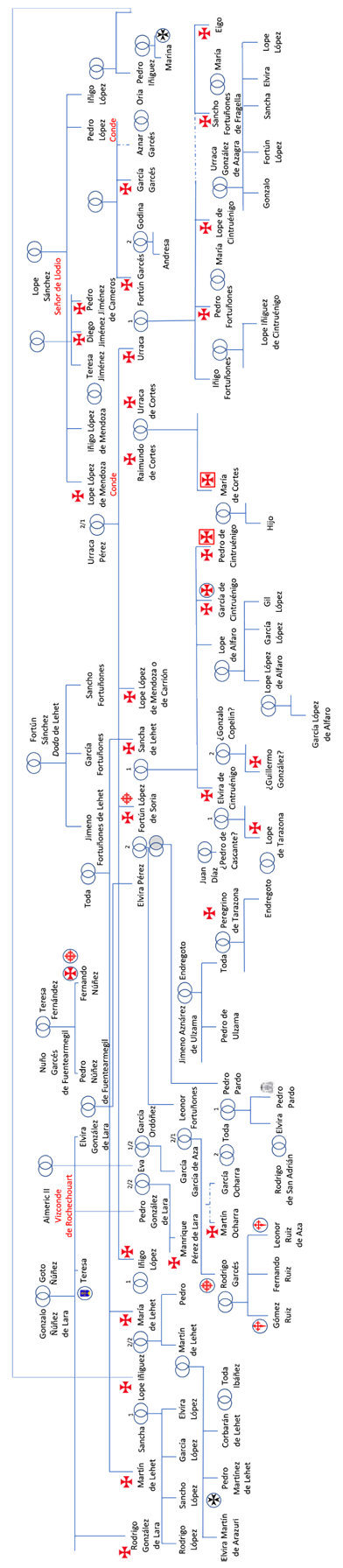

FIGURA 3. LINAJE DE FREY RODRIGO GARCÉS, MAESTRE DE LA ORDEN MILITAR DE CALATRAVA 


\section{BIBLIOGRAFÍA}

Asenjo GonzÁlez; María. Instituciones: poder, sociedad, gobierno y vecindad en Soria (siglos xiı al xiv). De las collaciones a las cuadrillas. En De la Casa Martínez, Carlos y Martín Marco, José Antonio (Coord.), Soria III9, Soria: Ayuntamiento de Soria, 20I9, pp. 305-330.

Cabanes Pecourt, $\mathrm{M}^{\mathrm{a}}$. Desamparados. Rodericus Ximenius de Rada: Opera. Zaragoza: Anubar. Calleja Puerta, Miguel. «La autoridad de lo escrito en la Primera Crónica Anónima de Sahagún». E-Spania (Ejemplar dedicado a: Primera Crónica anónima de Sahagún / Autoriser le récit historique. Sous la direction de Hélène THIEulin-Pardo), n. I9, I9 de octubre de 2014 (Cfr. https://journals.openedition.org/e-spania/23828 consultada al preparar este trabajo).

CANEllas López, Ángel (I963-I965). «Tarazona y sus gentes en el siglo xil». Cuadernos de historia, Jerónimo Zurita, n. I6-18, pp. 27-47.

Corral Lafuente, José Luis. «Alfonso I el Batallador, la ciudad de Soria y su territorio». En De la Casa Martínez, Carlos y Martín Marco, José Antonio (Coord.), Soria III9, Soria: Ayuntamiento de Soria, 2019, pp. 9I-Io8.

Ferrer-Vidal Díaz del Reguero, María Soledad. «Santa Eufemia de Cozuelos: un monasterio femenino de la Orden Militar de Santiago». En la España Medieval (Ejemplar dedicado a: En memoria de Salvador de Moxó (I)), n. 2, I982, pp. 337-348.

Fortún PÉrez de Ciriza, Luis Javier. Sancho vil el Fuerte (II94-I234). Iruña: Mintzoa, I986.

García IzQuierdo, Iván. «El linaje de Aza. Origen, evolución e impacto de una familia aristocrática en la Castilla suroriental». Studia histórica. Historia medieval, v. 35, n. I, 20I7, pp. I29-I55.

González González, Julio. El reino de Castilla en la época de Alfonso VIII. Tomo I: Estudio. Madrid: Consejo Superior de Investigaciones Científicas, I960.

JAURGAIN, Jean de. «Toponymie basque», en Eusko ikaskuntzen nazioarteko aldizkaria / Revue internationale des études basques / International journal on Basque studies, volumen 6, número 2, I9I4, pp. I6I-I7I.

Lema Pueyo, José Ángel. Colección diplomática de Alfonso I de Aragón y Pamplona (IIO4-II34). San Sebastián: Sociedad de Estudios Vascos, I990.

Lema Pueyo, José Ángel. «El itinerario de Alfonso I 'El batallador' (IIO4-II34)». Historia. Instituciones. Documentos, n. 24, I997, pp. 333-354.

Martín Duque, Ángel. Documentación medieval de Leire (siglos IX a XII). Pamplona: Gobierno de Navarra, I983.

Martínez Díez, Gonzalo. «El Fuero de Soria: Génesis y fuentes», Anuario de historia del derecho español, n. 76, 2006, pp. 9-32.

Mugueta Moreno, İñigo. «La nobleza en Navarra (siglos xill-xıv): Una identidad militar». Iura vasconiae, n. 4, 2007, pp. 189-238.

NUÑo GonZÁlez, Jaime. «La repoblación de la ciudad de Soria: cuestiones de geografía y topografía». En De la Casa Martínez, Carlos y Martín Marco, José Antonio (Coord.), Soria III9, Soria: Ayuntamiento de Soria, 2019, pp. 177-223.

Olcoz Yanguas, Serafín. «İñigo y Fortún López: los dos primeros tenentes de Soria, durante el reinado de Alfonso I de Aragón y Pamplona». Berceo, n. I74, 2018, pp. 269-292.

Olcoz YanguAs, Serafín. «Cuatro Lope López en el reino de Aragón y Pamplona: el origen del linaje Almoravid, y sus relaciones con Liédena, Calahorra y otras tenencias del valle del río Ebro. Kalakorikos, n. 23, 2018, pp. 243-265. 
Olcoz Yanguas, Serafín. Los orígenes del Temple en el valle medio de Ebro: Antecedentes de la Orden del Cister y de la Orden Militar de Calatrava. Tudela: Ayuntamiento de Fitero, 2019.

Pavón Benito, Julia. Poblamiento altomedieval navarro: base socioeconómica del espacio monárquico. Pamplona: EUNSA, 2000.

Pavón Benito, Julia. «La encomienda sanjuanista de Leache en la Edad Media. Una primera aproximación». Príncipe de Viana, (Ejemplar dedicado a: VII Congreso General de Historia de Navarra (Vol. I)), n. 253, 20II, pp. 279-294.

Rades Andrada, Francisco. Chronica de las tres Ordenes y Cauallerias de Sanctiago, Calatraua y Alcántara: en la qual se trata de su origen y sucesso, y notables hechos en armas de los Maestres y Caualleros de ellas: y de muchos Señores de Titulo y otros Nobles que descienden de los Maestres: y de muchos Linages de España. Compuesta por el Licenciado Frey Francisco de Rades y Andrada, Capellan de su Magestad, de la Orden de Calatraua. Dirigida a la C.R.M. del Rey don Philippe nuestro señor, Administrador perpetuo destas Ordenes. Toledo: Casa de Juan Ayala, I572.

Remírez Vallejo, Salvador. «Mulieres Templi. Cofradesas y donadas del Temple en el reino de Navarra (siglo XII)». Príncipe de Viana, n. 273, 20I9, pp. 93-II4.

Rodríguez-Picavea Matilla, Enrique. La formación del feudalismo en la meseta meridional castellana: Los señoríos de la Orden de Calatrava en los siglos XII-XIII. Madrid: Siglo Veintiuno, I994.

SalazAr Acha, Jaime. «El linaje castellano de Castro en el siglo xil: consideraciones e hipótesis sobre su origen». Anales de la Real Academia Matritense de Heráldica y Genealogía, n. I, I99I, pp. 36-68.

Soriano Calvo, Gilberto. «De la fundación o población de Soria». En De la Casa Martínez, Carlos y Martín Marco, José Antonio (Coord.), Soria III9, Soria: Ayuntamiento de Soria, 20I9, pp. II-47.

Soriano CALvo, Gilberto. «Influencia de las redes nobiliarias en la expansión cristiana del siglo XII. El caso de Soria». Espacio, tiempo y forma. Serie III, Historia medieval, n. 33, 2020, pp. 579-612.

Ubieto Arteta, Agustín. Los tenentes de Aragón y Navarra en los siglos XI y XII. Valencia: Anubar, I973. 

Calidad de Revistas

científicas Españolas

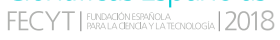

SERIE III HISTORIA MEDIEVAL

REVISTA DE LA FACULTAD DE GEOGRAFİA E HISTORIA
AÑO 2021

ISSN: 0214-9745

E-ISSN 2340-1362

\section{4 \\ issacio. \\ TIEMPO \\ Y FORMA}

\section{Volumen I}

\section{Artículos · Articles}

15 Patricia A. Argüelles Álvarez

Peligros, inseguridades y problemas del viajero visigodo

37 Carmen Barceló, Ana labarta, Josep Benedito \& José M. MELCHOR

Cuatro cerámicas con epigrafía árabe del Museu de Borriana

65 CARlos BARQuero Goñ

Organización de la Orden de San Juan en Castilla durante los siglos XII y XIII

113 Francisco de Paula Cañas Gálvez

Una infanta de Navarra en la corte de Castilla: escenarios políticos en torno a la configuración y evolución del Hostal y la casa de Blanca de Trastámara, Princesa de Asturias (1424-†1464)

\section{David Caramazana Malia}

Las promociones artísticas de Alonso de Ejea, arzobispo y administrador perpetuo de la Archidiócesis de Sevilla y patriarca de Constantinopla (1403-1417)

\section{Pedro Castillo Maldonado}

Privilegios episcopales: la inviolabilidad de los obispos visigóticos y el delito de lesa majestad

\section{MÁxIMO DIAGO HERNANDO}

Alonso de Fonseca, Obispo de Ávila, Cuenca y Osma, y el ascenso de un linaje de exiliados portugueses en la Castilla de los siglos XV y XVI

\section{Antonio PIO dI Cosmo}

Santa Brigida ed il Monte Gargano: un paesaggio dell'anima. La descrizione dell'ambiente come stratagemma d'ammaestramento morale

\section{FERRAN ESQUILACHE}

La 'fila' de agua valenciana y otras medidas de aforo. La verdadera naturaleza de un sistema de medición de caudales de origen andalusí

\section{Alejandro Esteban Álvarez}

Habices del Reino de Granada averiguados en 1528 y 1531: la țā'a nazarí de Órgiva (Alpujarra)

\section{JaVier Gómez Gómez \& IÑAKı MARTín VISO}

Rationes y decimas: evidencias sobre la gestión de las sernas en el siglo XI en el noroeste de la Península Ibérica
383 SANTIAGO GONZÁLEZ SÁNCHEZ

Aportaciones de Paredes de Nava a las campañas militares de Infante Don Fernando, señor de la villa y regente de Castilla, contra el Reino Nazarí de Granada en 1407 y en 1410

429 ANTONI LLIBRER ESCRIG

Una máquina para la industria medieval. Los batanes del sur valenciano: integración y negocio. Nuevas aportaciones (1490-1502)

455 José Miguel López Villalba Comunicación escrita y oral de la ordenanza municipa (siglos XV-XVI)

501 Emilio Martín Gutiérrez

El aprovechamiento de los recursos naturales: la grana en Andalucía occidental durante el siglo XV

\section{Volumen II}

537 VERA-CRuz Miranda MENACHO

$(1421-1461)$

Las finanzas de un heredero: Carlos de Aragón y Navarra

569 Raúl Morales Muñoz

Hacia una revalorización del conciliarismo hispano bajomedieval: el Defensorium Trium Conclusionum de Alfonso de Madrigal

605 David Nogales Rincón

Enrique III de Castilla (1390-1406) y la indagación de rentas: un proyecto regio para la búsqueda de mineros y tesoros a inicios de cuatrocientos

6.7.7 Gonzalo Oliva Manso

Seisenes y novenes. Tiempos de calma para la moneda castellano-leonesa (1282-1312)

685 Alberto Peña Fernández y Manuel García Alonso Una inscripción medieval inédita en la iglesia de San Miguel de Aguayo (Cantabria)

713 RODRIGO POUSA DIÉGUEZ

Configuración institucional de una villa costera: Muros en el tránsito de la Edad Media a la Edad Moderna

\subsection{JuAn A. Prieto Sayagués}

Las profesiones femeninas de la nobleza y de las oligarquías urbanas en la Castilla bajomedieval. Causas, dinámicas, privilegios y donaciones 


\section{4}

\section{ESPACIO,}

\section{TIEMPO}

Y FORMA

UกED

SERIE III HISTORIA MEDIEVAL

REVISTA DE LA FACULTAD DE GEOGRAFÍA E HISTORIA

815 María del Pilar Rábade Obradó

El miedo a la Inquisición en la Castilla de los Reyes Católicos

84.5 Carlos Manuel Reglero de la Fuente

EL abad contra el rey (y los regidores): conflicto de jurisdicciones y ejercicio del poder en Sahagún (1398-1417)

881 Manuel Alejandro Rodríguez de la Peña

Eusebius and Alcuin on Constantine and Charlemagne as Wise Rulers: Sapiential Rulership in Late Antiquity and the Early Middle Ages

9)15 Antonio SÁnCHEZ GonzÁlez

El Archivo de los Mariscales de Castilla y Marqueses de Malagón

\section{Estudios y comentarios}

9. 51 Serafín Olcoz Yanguas

Apostilla al estudio Influencia de las redes nobiliarias en la expansión cristiana del siglo XII: el caso de Soria (ETF, 33, 2020)

\section{Libros · Books}

969 CAstrillo CASAdo, Janire, Las mujeres vascas durante la Baja Edad Media (MARía Jesús Fuente)

973 Crónica del rey Juan II de Castilla. Minoría y primeros años de reinado (1406-1420) GARCIA, Michel (edición y estudio) (VÍctor MUÑ̃z GómEZ)

981 DA Silva, Marcelo Cândido, História Medieval (DIEgo CARLo AMÉNDOLLA SPÍNOLA)

9.87 Galende Díaz, Juan Carlos y Ávila SeoAne, Nicolás, El rodado regio hispánico. Fernando III de León y Castilla (12301252) (MAURICIO HERRERO JIMÉNEZ)

989 García IzQuierdo, Iván, Frontera, fuero y concejos. EI valle del Riaza en la Edad Media (siglos VIII-XII) (CARLOS BARQUERO GOÑI)

993 García IzQuierdo, Iván y Peterson, David (coords.), Camino y Señorío. Obra selecta de Luis Martínez García (ENRIQUe CANTERA MONTENEgRO)

995 GonzÁlez PAz, Carlos Andrés, O Bispado de Mondoñedo na Idade Media. Territorio, comunidade e poder (ENRIQUE CANTERA Montenegro) 


\section{4}

\section{ESPACIO,}

\section{TIEMPO}

Y FORMA

UกED

SERIE III HISTORIA MEDIEVAL

REVISTA DE LA FACULTAD DE GEOGRAFİA E HISTORIA

\section{Libros · Books}

9) López MARtínez, Amalia, Minutarios notariales de Estevo Pérez (Ourense, siglo XIV) (José MIgUel LóPEz VILLALBA)

999 Miranda García, Fermín y López de Guereño SAnz, María Teresa (eds.), La muerte de los príncipes en la Edad Media. Balance y perspectivas historiográficas (ANA ECHEVARRÍA ARSUAGA)

1003 Motis Dolader, Miguel Ángel, Vivencias, emocionesy perfiles femeninos. Judeoconversas e Inquisición en Aragón en el siglo XV (ANA ECHEVARría ARsuaga)

1007 Solórzano Telechea, Jesús Ángel y Martín PÉrez, Fernando (coords.), Rutas de comunicación marítima y terrestre en los reinos hispánicos durante la Baja Edad Media. Movilidad, conectividad y gobernanza (ENRIQUE JOSÉ RUIZ PILARES)

1013 TORRE, Sandra de la - ETXEBERRIA, Ekaitz - DíAz DE DURANA, José Ramón (coords.), Valer más en la tierra. Poder, violencia y linaje en el País Vasco bajomedieval (ENRIQUE CANTERA MONTENEGRO)

1015 TRILlo SAN José, Carmen, La Vega de Granada a partir de documentación árabe romanceada inédita (1457-1494). Estudio, edición e índices (INMACULADA GONZÁLEZ SOPEÑA)

1019 Val Valdivieso, M. ${ }^{a}$ Isabel - VillanueVa ZubizarReta, Olatz (Coords.), Pero Ansúrez. El conde, su época y su memoria (ENRIQUe CANTERA MONTENEGRO)

1021 Villanueva Morte, Concepción y Fernández de Córdova Miralles, Álvaro, El embajador Claver. Diplomacia y conflicto en las «Guerras de Italia» (1495-1504) (ENRIQUE Cantera Montenegro) 